\title{
Towards a Methodology for Evaluating Architectural Heritage Preservation Methods
}

\author{
Alanoud Abdulaziz Alansari ${ }^{1}$, Yousra Bin Mosaad ${ }^{2}$ and Kazuhiro Hirao ${ }^{3}$ \\ 1. Graduate School of Science and Engineering, Ritsyumeikan University, Kusatsu, Shiga 525-8577, Japan; \\ 2. Art and Design, Interior Design, King Abdulaziz University, Alrehab dist. Jeddah, Saudi Arabia; \\ 3. Department of Architecture and Urban Design, Ritsumeikan University, Shiga 525-8577, Japan
}

\begin{abstract}
The treatment of historical buildings represents challenges for those who are concerned with conservation. The difficulty lies in how to apply the treatment without destroying the old components and the original design of the building. The treatment processes take place by the classification of the type and the value of the building, then the determination of the deterioration level decides the level of intervention. The aim of the research is to provide a method for assessing the ways of preserving the architectural and urban heritage, which includes all the factors that affect the preservation of the heritage so as to access that it contributes to access to the deficiencies in the ways of preserving the heritage and to build a plan for action to avoid them in the future. The research followed a causal comparative research approach that began with an analytical study to determine the factors affecting preservation and its considerations, by collecting and analyzing the data of the most important international and national charters and recommendations for the preservation. This study defined the preservation works into 4 levels of interventions passed on the intervention objectives, building's physical state, causes for the deterioration and maintenance works. By comparing the deterioration level with the intervention level for the conservation procedures, the result indicates the suitability of the work performed. This result could be number between 4 and -4 .
\end{abstract}

Key words: Preservation, architectural heritage, conservation, evaluation.

\section{Introduction}

The research is directed towards studying and analyzing the relationship between the causes of restoration and reconstruction that occurred to the building during a given period of time. The extent of the changes brought about by these operations in the building's form and characteristics illustrates the impact of the approach, which is followed in the maintenance of the building. In addition, this research assesses the restoration operations in accordance with the modern approach followed in maintaining the archeological buildings.

The research provides a clarification on the concept and importance of maintenance to the historic buildings, and the need for their completion without

Corresponding author: Alanoud Abdulaziz Alansari, M.Sc.; research field: architectural design. E-mail: alanoud.alansari@gmail.com. compromising the original components and form of the building as much as possible. Furthermore, this research provides an explanation about the causes of the historic buildings' deterioration and the restoration levels consistent with the type and level of damage to the historic building.

In general, the current study helps to create a tool that clarifies the statistically significant relationship between the intervention in the building and the changes that have occurred to its form and components during a period of time.

Furthermore, the study aims in particular to study the impact of the approach taken in the restoration operations that were conducted to preserve the building; in addition to studying the extent of its impact on the original components and form of the building. It also contributes in coming up with assessments and proposals that can be applied to maintain the valuable 
historic buildings that have been recently discovered in some regions of Saudi Arabia to contribute in achieving one of the most important objectives of Saudi Vision 2030 represented in the revival of the national, Arab, and Islamic heritage sites and their registration in the World Heritage List.

\section{Previous Studies}

Giovanni Carbonara says about preservation: "It has several meanings in the technical language, sometimes giving meaning to maintenance, and in other cases, it means caring for the surroundings, such as the environment, problems of urban planning and laws related to the permanence of the archaeological building, The American Institute of Conservation determines conservation as follows: The profession that consecrates the preservation of heritage property for the future, includes the skills of preservation examination, documentation, treatments and preventive care that support research and education" [1].

Although there are many definitions of conservation, there is considerable agreement on the basic concept of conservation. It can be said that the concept of preservation is the process that includes all the procedures and methods that allow the inheritance to survive for as long as possible, so that it plays a role in the life of the society in which it coexists. In other words, conservation is only two parallel processes:

(1) First, it aims to preserve all that is valuable in shaping the physical and moral characters of the heritage domain;
(2) Second, it aims to control and necessarily influence the changes associated with the processes of development in which the heritage domain is subject [2].

The policy of dealing with urban and architectural heritage is divided into two levels: policies for the preservation of heritage buildings and policies for the preservation of heritage areas. International attention has begun to develop common principles for the regulation of international cooperation in heritage conservation. Several charters, recommendations, and resolutions have been issued by local and international bodies and organizations [3].

The classification of valuable buildings differs between a building with a technical value, a building linked to an important character, a building that expresses power, a visually and culturally distinguished building, a building linked to important events, and a fully historical and archaeological building (Fig. 1) [4].

In general, the buildings development policy includes ten phases undergone by the archaeological building, according to the work plan aimed at its development. The first phase begins, which is summarized in the building's valuation, followed by the documentation and submission phase for the building as a whole from its structure, design and raw materials; in order to determine the extent of the deterioration, and then comes the development objectives determination phase, which may aim to maintain the landmarks, develop the building or the material gain or improve the location's environment.

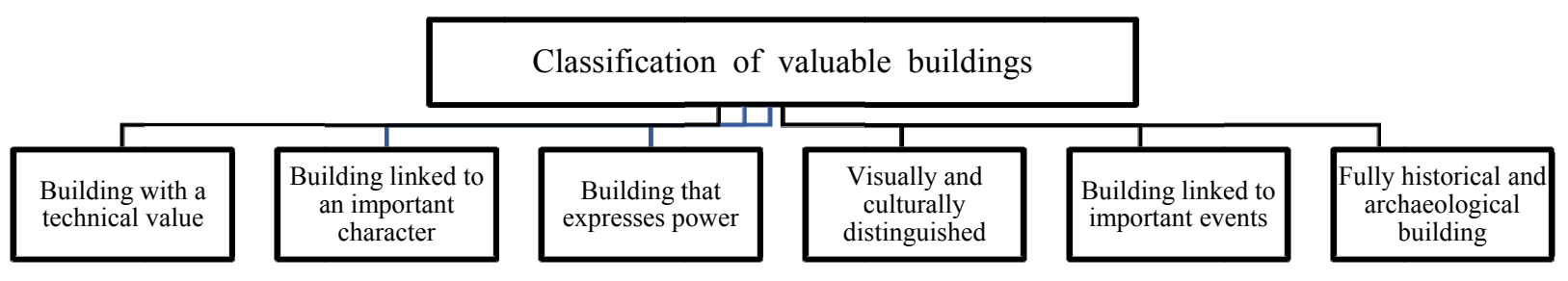

Fig. 1 The classification of the archaeological buildings. 
This is followed by determining the selection criteria from cost, funding sources, technology, profession, construction, and others, and then determining the income level, then determining the preservation elements, followed by assessing and analyzing the alternatives according to the substantive standards, and then choosing the most suitable for implementation (Fig. 2).

\section{Methodology}

The research follows the causal comparative methods or ex-post facto methods, which "seeks to find relationship between independent and variable after an action or event has already occurred, the researcher goal is to determine whether the independent variable is affected, by comparing two

\begin{tabular}{|c|c|c|}
\hline \multirow{3}{*}{$\begin{array}{l}\text { The work plan } \\
\text { phases for the } \\
\text { development } \\
\text { operation }\end{array}$} & \multirow[t]{3}{*}{ Building's valuation } & Historical value \\
\hline & & Artistic value \\
\hline & & Scientific value \\
\hline & \multirow[t]{3}{*}{ Documentation and submission } & Construction \\
\hline & & Design \\
\hline & & Raw materials \\
\hline & \multirow[t]{4}{*}{ Development objectives determination } & Maintaining landmarks \\
\hline & & Development \\
\hline & & Material gain \\
\hline & & Improvement of the location's environment \\
\hline & \multirow{8}{*}{ Determination of the selection criteria } & Cost \\
\hline & & Finance \\
\hline & & Site \\
\hline & & Structural conditions \\
\hline & & Population \\
\hline & & Two oceans \\
\hline & & Construction \\
\hline & & Profession \\
\hline & \multicolumn{2}{|l|}{ Determination of income level } \\
\hline & \multicolumn{2}{|l|}{$\begin{array}{l}\text { Determination of perservation } \\
\text { elements }\end{array}$} \\
\hline & \multicolumn{2}{|l|}{ Alternatives assessment } \\
\hline & \multicolumn{2}{|l|}{$\begin{array}{l}\text { Alternatives analysis according to } \\
\text { substantive standards }\end{array}$} \\
\hline & \multicolumn{2}{|l|}{$\begin{array}{l}\text { Alternatives assessment and selection } \\
\text { of the most suitable }\end{array}$} \\
\hline & \multicolumn{2}{|l|}{ Implementation } \\
\hline
\end{tabular}

Fig. 2 Historic buildings development policy. 
or more groups of individuals" [5].

An analytical study identifies the factors that affect conservation and its considerations, to follow the stages of conservation procedures for architectural heritage have been done, the research aims to establish a critical analysis approach to analyze the architectural heritage preservation methods to determine the pros and cons of these methods and to measure and evaluate them.

\section{Discussion}

The preservation work levels concerning the valuable archaeological building (Fig. 3) are divided into four levels:

(1) First level: it refers to the building materials and here, there are five categories. Maintenance, which aims to prolong the lifespan of the building materials; and it is divided into two parts: the expected preventive or corrective maintenance and the sudden maintenance; the prevention, which aims to provide maintenance to what is intended to be preserved, and that is in its same original condition by reducing the restorations made to the building as much as possible and protecting the building materials from decay; the deterioration prevention, which help in controlling the internal building's environment and preventing arson and vandalism; the restoration, which includes removing the additions and restoring the building to its natural state; the consolidation, which ensures the safety of the structure from decay or damage;

(2) Second level: the reconstruction, which restores the original form of the building by assembling parts or rebuilding or moving the building to another location; the remodeling to restore the original characteristics of the building; the recreate for the building from the extraneous elements that have been added to the building after a long time from its establishment; the integration of the missing parts of the building to complete the visual image; the saving by disassembling the building as a whole or divided into several parts and then transport them to a more suitable new location; and the replacement for the building, which occurs in

The architectural development and preservation of the valuable archaeological buildings

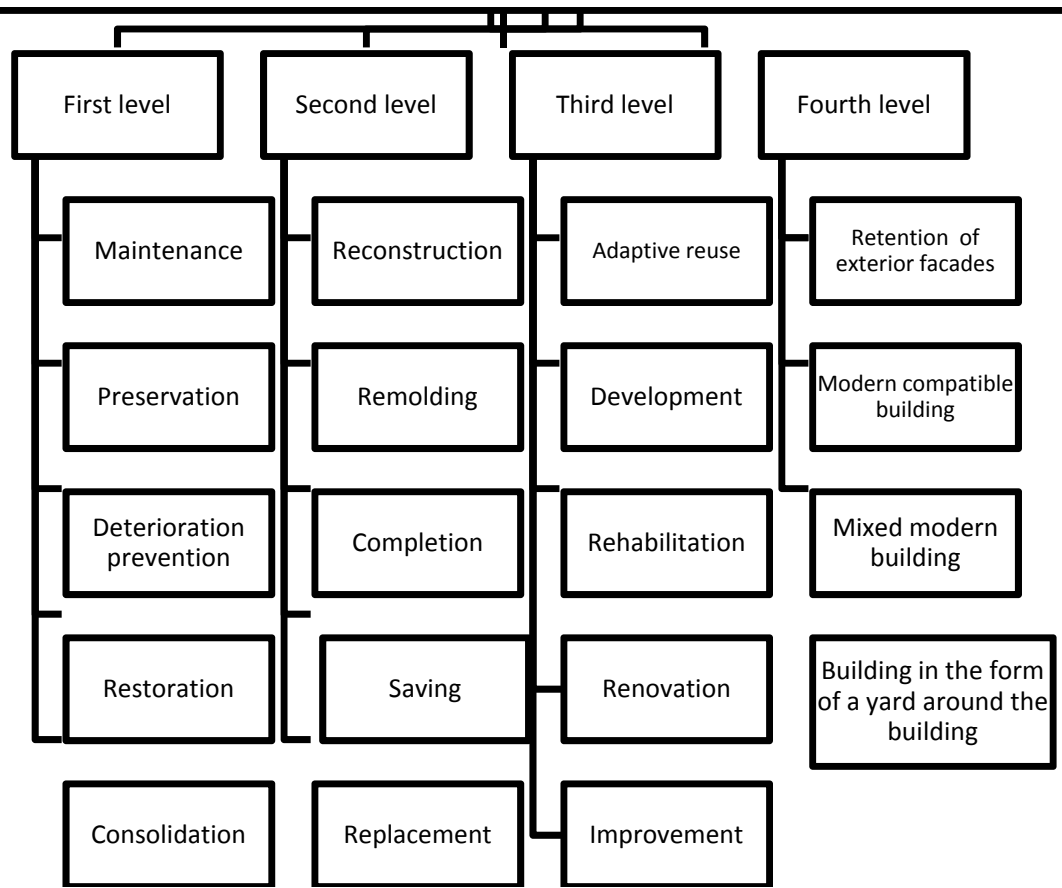

Fig. 3 Intervention and preservation levels. 
the event of a building's collapse or the invalidity of the materials for the new functions of the building;

(3) Third level: it includes the operations that relate to the building's functions such as the adaptive reuse, which are summarized in converting the functionality of a particular building into another function, while making the necessary modifications; the development, i.e., operations not related to the building's condition, but aims to improve the building to meet the functional needs and the rise in the activity levels [6]; the rehabilitation, which relates to the deteriorated buildings as a result of natural and abnormal factors that led to the building's hindrance in performing its functions; the renovation, which includes the organic and spiritual renovation of the building and the surrounding area, the re-embodiment of the internal and external spaces and the strengthening of the structure; and the improvement, which aims to make an extension for the building, while maintaining the roads and construction materials, or establish a modern building in the same area to fit with the increased functional requirements;

(4) Fourth level: it includes the development and radical change work, while keeping the external facades, establishing a modern building annexed to the building or a yard around the building using the new building materials.

The reasons behind the deterioration of the valuable buildings are its lifespan, which usually causes the physical deterioration for building's materials and structure (first and second levels), in addition to the natural factors of erosion, climate and groundwater, geological factors, and human factors from accidents, fires, lack of knowledge in preservation and development, negligence and vandalism. Both natural and human factors usually cause a physical deterioration in the building's materials and structure, and a functional deterioration (first, second and third levels), along with the emergence of stressors on the building as a result of change in the type and intensity of the users, which is considered a functional deterioration (third level) (Fig. 4).

The building's physical state affects the intervention level; as the building may be wholly or partly dilapidated; thus requiring the intervention and restoration of the building by one of the operations

\section{Causes of the deterioration of valuable buildings}

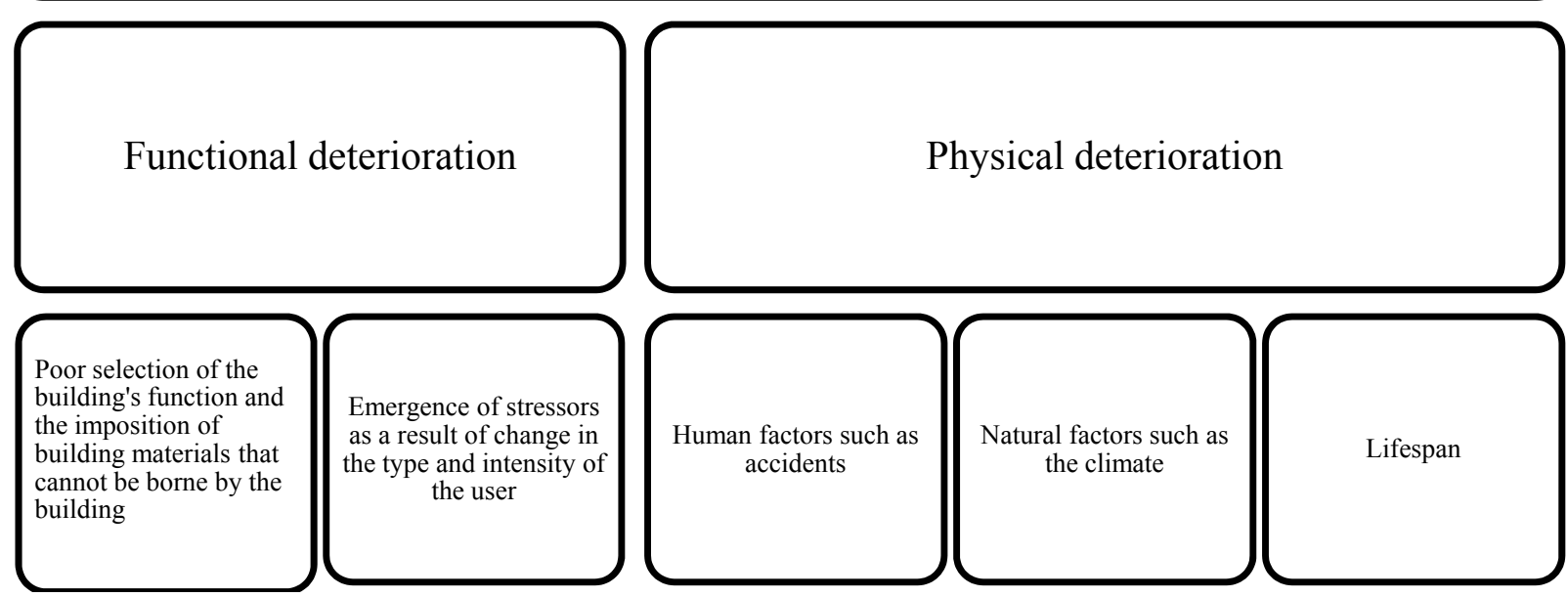

Fig. 4 Causes of the deterioration of the valuable buildings. 
described in the second level or using the addition and change method under the third level of the intervention levels as needed. However, if the building is subject to negative effects, this calls for intervention on the first level or the use of the development method under the third level. If the building was in good condition both internally and externally, it is possible to use some of the methods of the third level, and if the building only remains in good condition externally, it is likely to use the repair methods on the third, fourth and fifth levels as needed [7].

The intervention objectives are limited to five objectives that influence the determination of the preservation work level, and it may aim to protect the landmark and maintain its original features; this requires preservation work on the first level, while in case of the restoration of the building's original features, the preservation work will be restricted to the second level. If the objective is to rehabilitate the building, the preservation work will be performed on the third level. If the objective is to protect and maintain the exterior facades, then the preservation work performed on the fourth level will be used, and the preservation operations on the fifth level will be used in case of desiring horizontal expansion and extending the building.

The preservation work that can be done is diversified, and the most important of which is the replacement of the deteriorated parts with similar ones; this action is taken to make changes using the preservation methods on the first level. Among the preservation works is the re-establishment of the entire building to become an image of what it used to be, and so one of the preservation methods on the second level will be used. From the other preservation work, what can be done is to find the spaces for additional activities and re-formulating these spaces, and so one of the preservation methods on the third level will be used.

The reasons behind the deterioration, the building's physical state, the intervention objectives and the

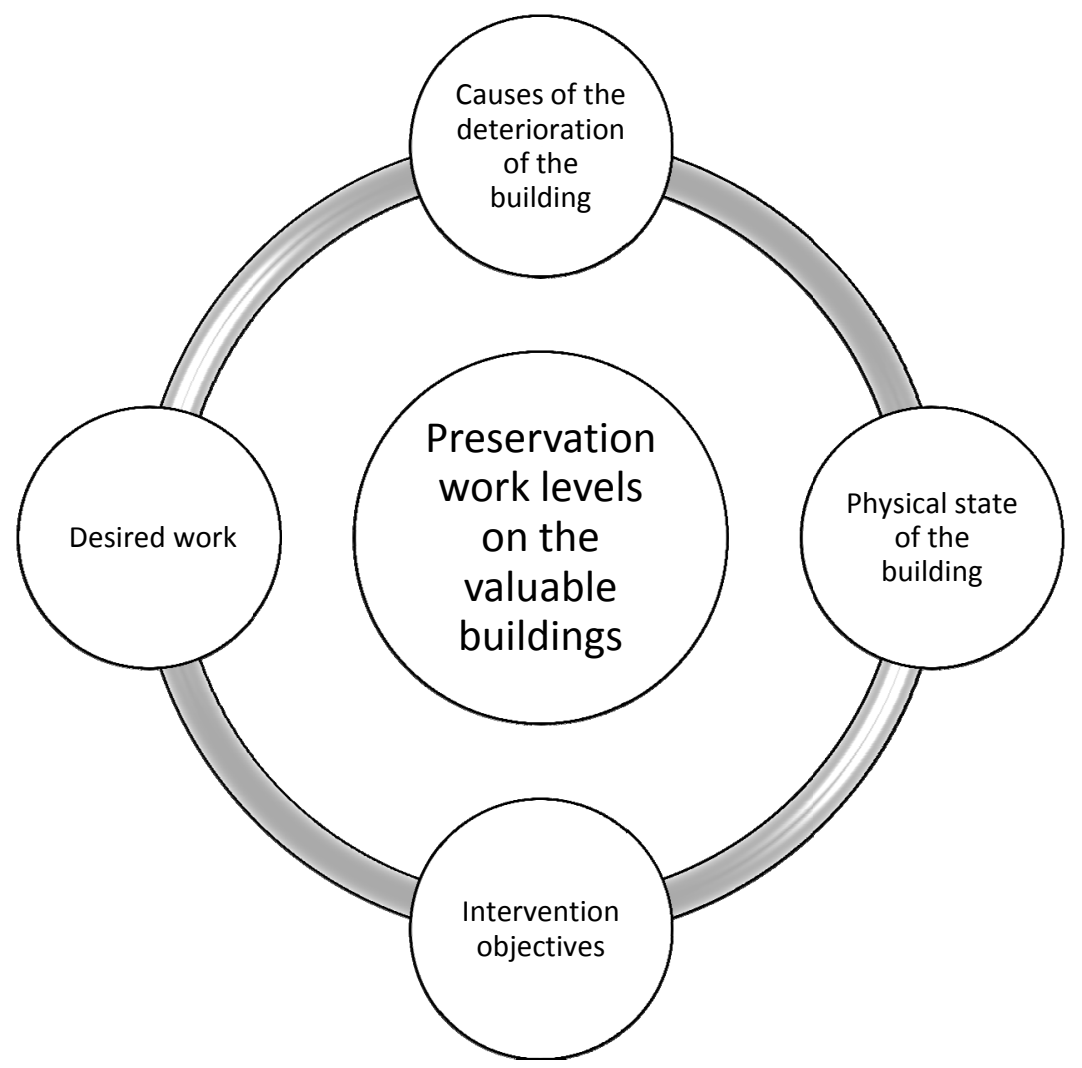

Fig. 5 Determinants of the intervention levels in the valuable buildings value. 
preservation work that can be done is the factors that determine the intervention levels in the valuable buildings (Fig. 5).

\section{Results and Recommendations}

The designed strategy works on assessing the restoration operation performed to the buildings of a historical nature by assessing them according to one of four different levels, and then comparing them with the extent of deterioration incurred by the building, and that is after assessing the type and size of deterioration at the four different levels, with the aim of comparing the deterioration level with the intervention level through the following equation:

Intervention Level - Deterioration Level (Fig. 6)

(1) Deterioration Level - Intervention Level $=$ Zero $\Rightarrow$ indicates the suitability of the work performed for the building and its incurred deterioration at the time;

(2) Deterioration Level - Intervention Level > Zero $\Rightarrow$ indicates the unsuitability of the work performed for the building and its incurred deterioration at the time and it is applying a minimal intervention to restore the building;

(3) Deterioration Level - Intervention Level < Zero $\Rightarrow$ indicates the unsuitability of the work performed for the building and its incurred deterioration at the time and it is applying an over-intervention to restore the building.

The analyzed data were collected to create the preservation matrix (Table 1), which was inspired by a number of studies concerning the preservation of the architectural heritage. It is a practical methodology for assessing the restoration operations, its objectives and the relationship between the extent and the causes of deterioration with the restoration operation that followed.

This matrix can be used by any researcher concerned with determining the intervention level in conservation procedures, performing a calculation on any restoration operation under the study that could be done. This will help to find a course showing the relationship between the deterioration level and the intervention level within the temporal boundaries of the research. Also, it is advisable to do a calculation of the average of the intervention level and the deterioration level for all operations, and perform the same calculation to reach a general conclusion for the research.

From the above, by using this matrix, the preservation institutions can pinpoint the problems with previous preservation procedures and help to improve upcoming procedures. This insight may greatly contribute to changing the actual reality in the experiment of preserving the architectural heritage according to Saudi Vision 2030 which includes the plan to support the preservation methods of the architectural and urban heritage in the region, in accordance with a clear and locally acceptable methodology. These problems might be identified based on the shortage that emerged in the preservation methods of the architectural heritage in the building experiment after the application of the proposed approach.

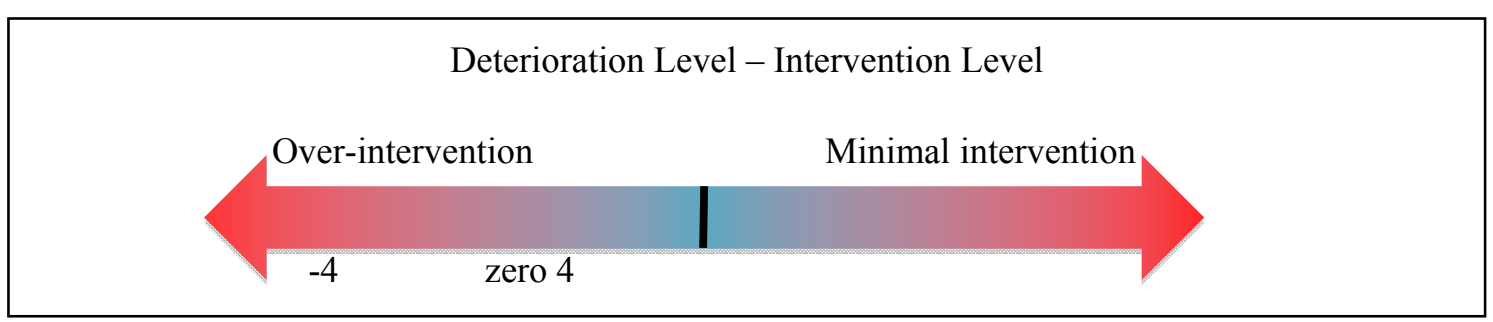

Fig. 6 Equation measuring the suitability of restoration for the deterioration level. 
Table 1 Preservation matrix.

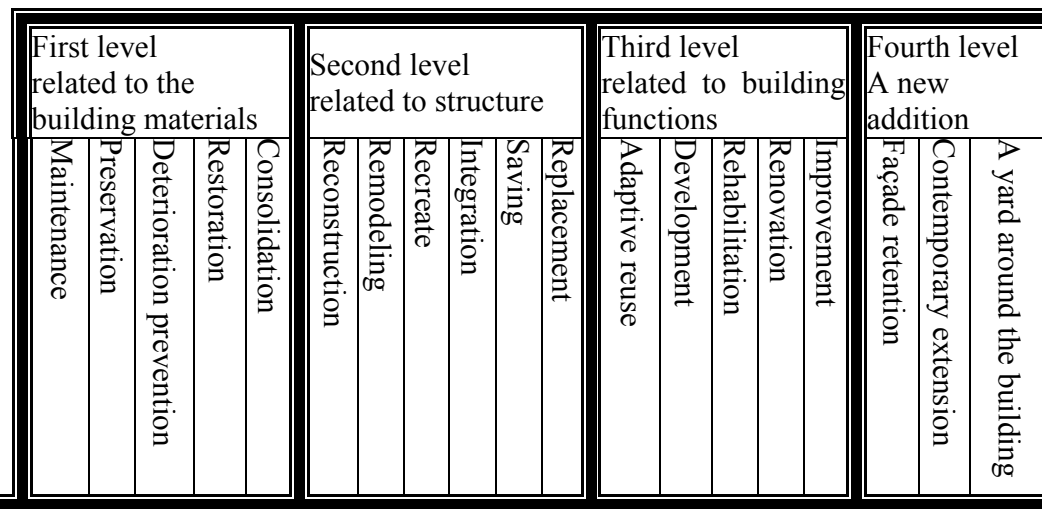

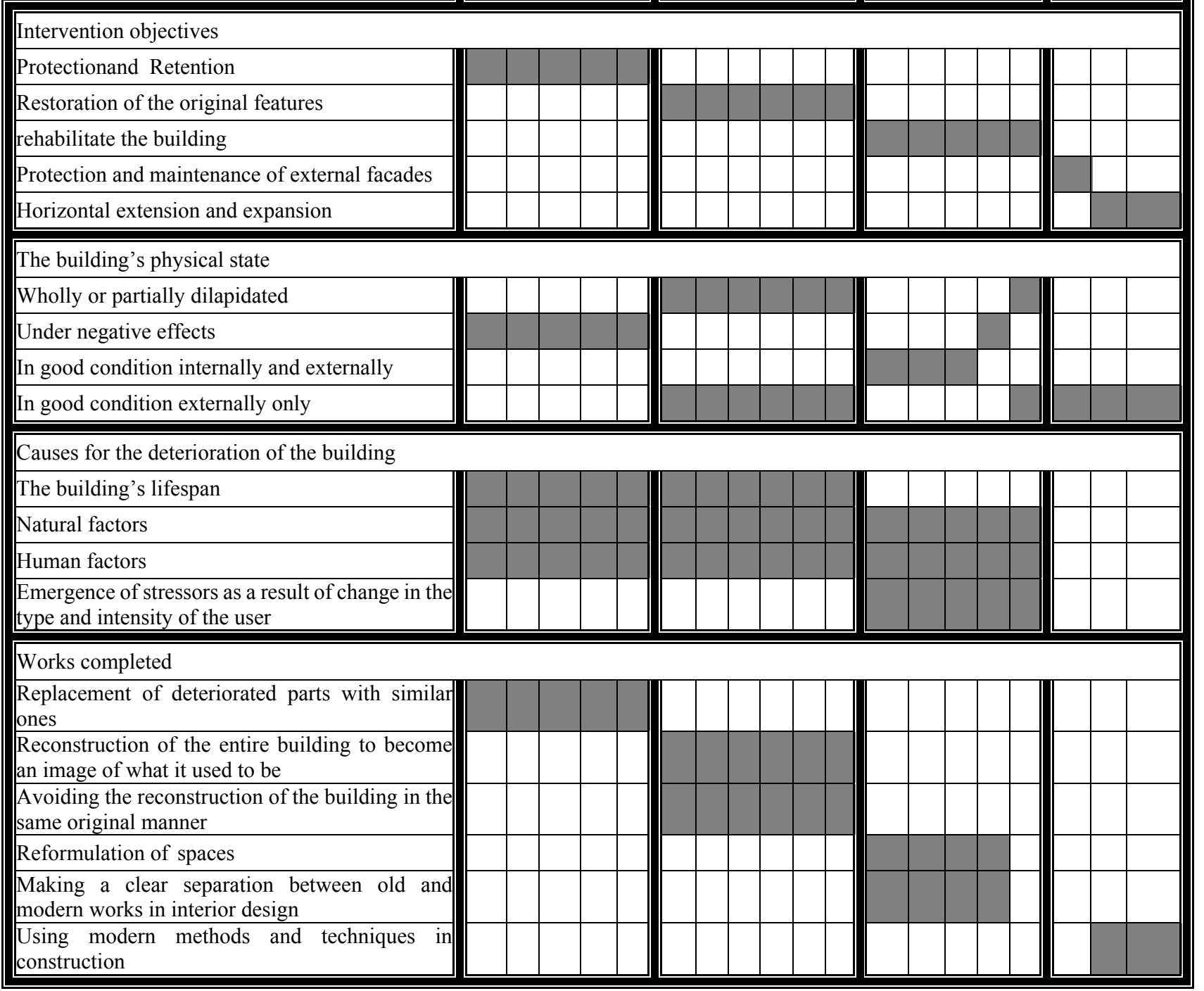




\section{Conclusion}

In this study, it is possible to clarify the deficiency in the application of architectural heritage preservation methods according to the approach suggested.

This study also contributes to the formulation of conservation matrix, which formed the theoretical basis for dealing with the conservation of architectural heritage. It is also the basis for the analysis, classification and evaluation for the operations under the study - a systematic approach that can be applied to maintain the valuable historic buildings that have been recently discovered in some regions of Saudi Arabia to contribute in achieving one of the most important objectives of Saudi Vision 2030 represented in the revival of the national historical buildings.

\section{References}

[1] Alian, J. 2005. Conservation of Cultural Heritage. Kuwait: Knowledge World. (in Arabic)

[2] Al-Khadrawi, R. 2003. "Conservation of Urban Heritage to Achieve Sustainable Tourism Development through Civil Society Institutions.” Master thesis, Cairo University. (in Arabic)

[3] Abdel-Hayy, N. 2015. "Towards a Methodology to Preserve Architectural and Urban History in Greater Khartoum.” Ph.D. thesis, Sudan University of Science and Technology. (in Arabic)

[4] Afifi, A. 2013. "Environmentally Compatible Architecture as an Approach to Preservation of Heritage Buildings in Egypt." Master thesis, Ain Shams University. (in Arabic)

[5] Salkind, N. J. 2010. "Causal Comparative Design." Encyclopedia of Research Design 1: 124-31.

[6] Ali, A. 2013. "Reuse of Archaeological Buildings." Master thesis, Cairo University. (in Arabic)

[7] Amer, A. 2012. "Minimal Intervention as a Principle to Preserve Buildings and Historic Areas Case Study of the Red Dar Al-Ahmar Area, Cairo." Presented at the 3rd National Urban Heritage Symposium. (in Arabic) 